\title{
RANDOMLY AMPLIFIED POLYMORPHIC DNA-A BRIEF REVIEW
}

\author{
Nandani Kumari and Saroj Kumar Thakur \\ Department of Animal Breeding and Genetics, \\ Ranchi Veterinary College, Birsa Agricultural University, Jharkhand, 835240, India
}

Received 2013-08-01; Revised 2013-09-19; Accepted 2014-01-02

\begin{abstract}
RAPD is a PCR based technique which involves the use of single arbitrary short primers (8-12 nucleotides), resulting in the amplification of many discrete DNA. The segments of DNA that are amplified are random. The technique was developed independently by two different laboratories and called as RAPD and AP-PCR (Arbitrary Primed PCR). This procedure detects nucleotide sequence polymorphisms in a DNA amplification based assay using only a single primer of arbitrary nucleotide sequence. The RAPD technology has provided a quick and efficient screen for DNA-sequence polymorphisms at a very large no of loci. The present communication gives emphasis on basic knowledge about RAPD, procedure, its advantages disadvantages, limitations and applications of RAPD.
\end{abstract}

Keywords: DNA, PCR, Polymorphism, Dendrogram, Genetic Diversity

\section{INTRODUCTION}

Estimation of genetic variations are increasingly being based upon information at the DNA level by various molecular techniques such as Randomly Amplified Polymorphic DNA (RAPD), Amplified Fragment Length Polymorphism (AFLP), RFLP, SSR and microsatellite. Among them, RAPD, markers generated by Polymerase Chain Reaction (PCR) is widely used since 1990's to assess intra specific genetic variation at nuclear level (Welsh and McClellan, 1990). RAPD is a PCR based technique for identifying genetic variation. It involves use of single arbitrary primer in a PCR reaction, resulting in amplification of many discrete DNA. RAPD technology provides a quick and efficient screen for DNA sequence based polymorphism at a very large number of loci. The major advantage of RAPD includes that, it does not require pre-sequencing of DNA. The vast range of potential primers that can be used, give the technique great diagnostic power. Reproducible RAPD bands can be found by careful selection of primers, optimization of PCR condition for target species and replication to ensure that only reproducible bands are scored. RAPD analysis has been extensively used for various purposes which include identification and classification of accessions (Fukuoka et al., 1992), identification of breeds (Qian et al., 1996) and genetic diversity analysis (Yu and Paul, 1992; Mackill, 1995; Cao and Oard, 1997). The advent of Randomly Amplified Polymorphic DNA (RAPD) by Williams et al. (1990) provided new tool for the molecular geneticist.

In one study involving indigenous African cattle, Gwakiska et al. (1994) used RAPD markers to characterize the local Zebu cattle breeds of Tanzania. One of the primers ILO 11127 amplified RAPD fragment in $61 \%$ of the Tanzanyika short horned zebu animals but less than $6 \%$ in the other two breeds evaluated. Further the study revealed that ILO 1065 Primer could be a Bos indicus specified y-linked Polymorphism. They also showed that RAPD analysis could also detect introgression. Gwakiska et al. (1994); Shivakumar (1997) and Ahn et al. (1999) demonstrated breed specific RAPD bands in other species. Kantanen et al. (1995) concluded on the basis of his findings that goat Birsa Agricultural University, Jharkhand, 835240, India Tell: 09835396685 
breeds have a high degree of homogeneity. Kemp and Teale (1992) analyzed the data in Jamnapari and Black Bengal with Popgene. He found that in Jamnapari goat, genetic similarity is low within as well as between Black Bengal goats, but genetic distance is high between these two breeds. Cushwa et al. (1996) found that RAPD-PCR was a powerful molecular genetic technique for detection of genetic variability and similarity in different breeds/populations of livestock. Padmesh et al. (1998) RAPD analysis was done to determine intraspecific variability in Andrographis paniculata, a popular antipyretic and hepatoprotective drug used in traditional medicine in India. The accessions collected from parts of India and south-east Asia for molecular analysis revealed moderate variation within the species. Similarity measurement using UPGMA followed by cluster analysis resulted in 5 major groups based on geographical distribution that generally reflected expected trends between the genotypes. There were also important exceptions like AP-48, an accession from Thailand showing close resemblance to AP-38 collected from Tamil Nadu and AP-29 from Assam significantly diverged from the rest of the native genotypes. The results indicated that RAPD could be effectively used for genetic diversity analysis in wild species of prospective value as it is reliable, rapid and superior to those based on pedigree information Raghunathachari et al. (2000) studied a set of set of 18 accessions from an Indian scented rice (Oryza sativa L.) and they were subjected to random amplified polymorphic DNA (RAPD) analysis. Polymerase Chain Reaction (PCR) with 10 arbitrary oligonucleotide primers, applied to the 18 accessions, produced a total of 144 different marker bands of which $95.1 \%$ were polymorphic. The size range of the amplified DNAs was mostly between $0.5 \mathrm{kbp}$ and $4 \mathrm{kbp}$. Thus, with the selected primers sufficient polymorphism could be detected to allow identification of individual accessions. Visual examination of electrophoresis gels and analysis of banding patterns confirmed that many of the scented rice varieties under cultivation with similar names are genetically quite different. A dendrogram displaying the relative genetic similarities between the accessions showed a range of 25 to $77.5 \%$ similarity. The RAPD analysis offered a rapid and reliable method for the estimation of variability between different accessions which could be utilized by the breeders for further improvement of the scented rice genotypes. Rajora and Mosseler (2001) found out that, a central objective of genetic resources conservation is to maintain genetic integrity and natural levels of genetic diversity and to enhance genetic diversity in population and species where it has been eroded. He further stated that genetic diversity is essential for the long term survival of the species by populations because it provides the raw material for adoption and evolution, especially when environmental conditions have changed.

In a study by Muz et al. (2005) 30, 15 and 1 strains of Pasteurella multocida and 9, 8 and 6 strains of Mannheimia haemolytica from cattle, sheep and goats isolated in Elazig province located in the East of Turkey, respectively were typed by Random Amplified Polymorphic DNA (RAPD) assay using a random primer (OPA-11). By RAPD assay, two and three distinct band profiles were obtained in the examination of $P$. multocida isolates from cattle and sheep, respectively. However, M. haemolytica isolates from cattle, sheep and goats showed only one profile and these strains were not discriminated by RAPD. This study showed that little genetic heterogeneity exists among $P$. multocida and $M$. haemolytica isolates from lungs of cattle, sheep and goats. Khanuja et al. (2005) found that Nineteen Cymbopogon taxa belonging to 11 species, two varieties, one hybrid taxon and four unidentified species were analysed for their essential oil constituents and RAPD profiles to determine the extent of genetic similarity and thereby the phylogenetic relationships among them. Remarkable variation was observed in the essential oil yield ranging from $0.3 \%$ in Cymbopogon travancorensis Bor. to $1.2 \%$ in Cymbopogon martinii (Roxb.) Wats var. motia. Citral, major essential oil constituent, was employed as the base marker for chemotypic clustering.

RAPD stands for random amplification of polymorphic DNA and it is a type of PCR reaction in which the segments of DNA that are amplified are random and the primers used are short (8-12 nucleotides). No Knowledge of the DNA sequence for the targeted gene is required as the primers will bind somewhere in the sequence, but it is not certain exactly where. Rapd is a new technique based on PCR (Williams et al., 1990; Welsh and McClelland, 1990). It is a convenient, efficient and sensitive genetic marker for detecting the polymorphism of genome DNA. 10 base (GC-rich) oligonucleotide primers of arbitrary sequence were used in the PCR amplification and it can get amplification results of several loci.

\subsection{Principal of RAPD}

The standard RAPD technology (Williams et al., 1990) utilises short synthetic oligonucleotides (10 bases long) of random sequences as primers to amplify nanogram amounts of total genomic DNA under low 
annealing temperatures by PCR. Amplification products are generally separated on agarose gels and stained with ethidium bromide. Decamer primers are commercially available from various sources (e.g., Operon Technologies Inc., Alameda, California). Welsh and McClelland (1990) independently developed a similar methodology using primers about 15 nucleotides long and different amplification and electrophoretic conditions from RAPD and called it the arbitrarily Primed Polymerase Chain Reaction (AP-PCR) technique. PCR amplification with primers shorter than 10 nucleotides DNA Amplification Fingerprinting (DAF) has also been used producing more complex DNA fingerprinting profiles (Caetano-Annoles et al., 1991). Although these approaches are different with respect to the length of the random primers, amplification conditions and visualisation methods, they all differ from the standard PCR condition (Erlich, 1989) in that only a single oligonucleotide of random sequence is employed and no prior knowledge of the genome subjected to analysis is required. At an appropriate annealing temperature during the thermal cycle, oligonucleotide primers of random sequence bind several priming sites on the complementary sequences in the template genomic DNA and produce discrete DNA products if these priming sites are within an amplifiable distance of each other. The profile of amplified DNA primarily depends on nucleotide sequence homology between the template DNA and oligonucleotide primer at the end of each amplified product.

\section{MATERIALS AND METHODS}

Important steps of RAPD can be summarized as follows.

\subsection{Extraction of DNA}

DNA is extracted by various methods. It also depends upon the species of animal under study but the basic procedure remains the same. Genomic DNA is basically extracted and purified from white blood cells using proteinase $\mathrm{K}$ digestion and standard phenol: Chloroform extraction as per the standard protocol described by Sambrook et al. (1989). Yadav and Yadav (2007) extracted DNA using the protocol of Clamp et al. (1993) with some modifications (Shashikanth, 1999).

\subsection{Quality and Quantity Check of Extracted DNA}

Quantity and quality of DNA is determined by U.V. Spectrophotometric method. Quality of the DNA was checked by the ratio between OD260 and OD280 and also by $0.8 \%$ agarose gel electrophoresis.

\subsection{Selection of Primers}

Random Amplified Polymorphic DNA (RAPD) is a multiplex marker system that conventionally uses singleprimer PCR to amplify random DNA fragments. Because of its multiplex nature, it is frequently used in Bulked Segregant Analysis (BSA). In view of the very large numbers of markers BSA often requires the use of mixtures of primers as a method of increasing the number of markers available. Theoretically, if a singleprimer reaction produces $\mathrm{x}$ bands on average, an unrestrained PCR process using a primers should produce $\mathrm{xa}^{2}$ bands. A total of 40 random oligonucleotide primers were used for amplification. All the random primers were $10 \mathrm{bp}$ long and with high GC content and were custom synthesized from M/s Bangalore Genei, Bangalore, India a Yadav and Yadav (2007). The standard RAPD technology utilises short synthetic oligonucleotides (10 bases long) of random sequences as primers to amplify nanogram amounts of total genomic DNA under low annealing temperatures by PCR.

\subsection{PCR Amplification}

The polymerase Chain Reaction (PCR) is a relatively simple but powerful technique that amplifies a DNA template to produce multiple copies of specific DNA fragment in vitro. PCR amplification consists of following 3 steps:

- DENATURATION-In PCRs catalyzed by Taq DNA polymerase, denaturation was carried out at $94^{\circ} \mathrm{C}$. During the denaturation, the first part of process, the double strand melted and opened to a single stranded DNA

- ANNEALING-Annealing is carried out at 38$35^{\circ} \mathrm{C}$ in touch down fashion for $30 \mathrm{~min}\left(3-5^{\circ} \mathrm{C}\right.$ lower than the calculated melting temp at which the oligonucleotide primers dissociate from their templates). In the PCR reaction carried out, the primers binded or "annealed" to the ends of the DNA strands at the temp up to $34-42^{\circ} \mathrm{C}$, (Kumari, 2010)

- EXTENSION-Extension of oligonucleotide primer is carried out at $72{ }^{\circ} \mathrm{C}$ (near the optimal temp for DNA synthesis catalyzed by the thermo stable polymerase). In case of Taq polymerase, the optimal temperature is $72^{\circ} \mathrm{C}$. The polymerization rate of Taq polymerase is $\sim 2000$ nucleotide/minute and at the 
optimal temperature $\left(72^{\circ} \mathrm{C}\right)$, extension is carried out for every $1000 \mathrm{bp}$ of the product, (Kumari, 2010)

The bases (complementary to the template) are coupled to the primer on the 3' end (the polymerase adds dNTP's from 5' to 3', reading the template from 3'to 5' side; bases are added complementary to the template). 1. Using fresh clean tips, all the reagents are added to an autoclaved microfuge tube placed on ice. A typical cocktail for PCR (1 reaction) consists of (Kumari, 2010):

- $10 \times$ Reaction Buffer $-1.5 \mu \mathrm{L}$

- DNTPs $(250 \mu \mathrm{M})-1 \mu \mathrm{L}$

- $\quad$ Primer $(10 \mu \mathrm{m})-2 \mu \mathrm{L}$

- $\quad$ Taq polymerase $-0.2 \mu \mathrm{L}$ (1 unit)

- $\mathrm{MgCl}_{2}-1.5 \mu \mathrm{L}$

- Genomic DNA -2 $\mu \mathrm{L}$

All the reagents are mixed, the appropriate cocktails for the desired number of samples are made and complete mixing is ensured by tapping the tube and quick spinning. About $2.0 \mu \mathrm{L}$ of the template DNA are added directly into the PCR tube for each reaction. The appropriate quantity of cocktail are pipetted directly into the bottom of the PCR tube $(0.2 \mathrm{~mL})$ containing the genomic DNA for each reaction. Adequate mixing of the cocktail in the tube is ensured. Tightly capped tubes are placed in the temperature block and it is made sure that each firmly seated by pressing on the tube individually. The PCR machine is programmed for the specific reaction conditions desired. After completion of the PCR reaction, the tubes are removed from the temperature block. The reaction products are separated according to size by agarose gel electrophoresis and visualized after staining the gel with ethidium bromide.

\subsection{Agarose Gel Electrophoresis of PCR Amplified DNA}

After completion of the PCR programme, the products are checked in $2 \%$ agarose for the amplification. Before loading into the wells, gel loading dye (bromophenol blue in glycerol) is added to the sample and the samples are run under constant voltage condition $(80 \mathrm{~V})$ till the two dyes get separated. Amplified products appear as sharp orange color bands under UV Transilluminator due to the intercalation of ethidium bromide. To ensure that the amplified DNA bands originated from genomic DNA and not primer artifacts, negative control are carried out for each primer/breed combination (Galli and Satti, 2009) No amplification is detected in control reactions. All amplification products are found to be reproducible when reactions are repeated using the same reaction conditions.

\subsection{Statistical Analysis}

\subsubsection{Determination of Genetic Variation within Population}

Genetic diversity within each population is determined as the observed and expected number of alleles (Kimura and Crow, 1964) and Shanon's Information Index (Lewontin, 1972) using Popgene software (Yeh et al., 1999).

\subsubsection{Neutrality Test for Markers}

Ewens-Watterson test was performed to test the neutrality for RAPD markers; the statistics F (sum of square of allelic frequency) and limit (upper and lower) at 95\% confidence region for the test were calculated using the algorithm by Manly (1985) using 1000 simulated samples and implemented in Popgene software package (Yeh et al., 1999; Weir and Cockerham, 1984).

\subsubsection{Genetic Differentiation}

In order to quantify the percentage of molecular variance due to difference among different populations and significance is tested by a non-random permutation approach described by Excoffier et al. (1992) using the AMOVA programme included in the Arlequin software package (Excoffier et al., 2007).

\subsubsection{Migration Rate}

The number of effective migrants per generation $\left(\mathrm{N}_{\mathrm{m}}\right)$ is calculated from the equation $\mathrm{N}_{\mathrm{m}}=0.25\{(1-$ $\left.\left.\mathrm{F}_{\mathrm{st}}\right) / \mathrm{F}_{\mathrm{st}}\right\}$. According to Kumari (2010), Gene flow (Nm) between Black Bengal type goat of Jharkhand and Black Bengal goat was 25.68, Hs (Mean sample gene diversity) between the two population was 0.412 and $\mathrm{Ht}$ (Total gene diversity) in total sample was 0.420 . A significant amount of differentiation among the two breeds and high level of gene flow between Jharkhand black and Black Bengal was observed by her.

\section{ADVANTAGES OF RAPD}

Main advantages of the RAPD technology include (i) suitability for work on anonymous genomes, (ii) applicability to problems where only limited quantities of DNA are available, (iii) efficiency and low expense. High number of fragments are formed. It is a simple technique. Arbitrary primers used for this technique can be easily purchased and there is no need for initial 
genetic or genomic information and the unit cost per assay is low. RAPDs have the advantage that they can be obtained at a reasonable cost and will generally amplify a range of fragments of most DNA and show polymorphisms. Certain primers will produce unrelated patterns between unrelated animals and identical ones for very closely related animals. Presumably, primer sites are randomly distributed along the target genome and flank both conserved and highly variable regions. Wide variation in band intensity can be shown to be reproducible between experiments, which could be the result of multiple copies of the amplified regions in the template or the efficiency with which particular regions are amplified. The polymorphic bands obtained from RAPDs can also be cloned for further analysis.

\section{DISADVAVTAGES OF RAPD}

RAPD markers are dominant. Amplification either occurs at a locus or it does not, leading to scores based on band presence or absence. This means that homozygotes and heterozygotes cannot be distinguished. In addition, the absence of a band through lack of a target sequence cannot be distinguished from that occurring through the lack of amplification for other reasons (e.g., poor quality DNA), contributing to ambiguity in the interpretation of results. Nothing is known about the identity of the amplification products unless the studies are supported by pedigree analysis. Problems with reproducibility result as RAPD suffers from sensitivity to changes in the quality of DNA, PCR components and PCR conditions, resulting in changes of the amplified fragments. Reproducible results may be obtained if care is taken to standardise the conditions used (Munthali et al., 1992; Lowe et al., 1996). Problems of co-migration raise questions like 'Do equal-sized bands correspond to DNA fragment'? The presence of a band of identical molecular weight in different individuals is not evidence per se that the individuals share the same (homologous) DNA fragment. A band detected on a gel as being single can comprise different amplification products. This is because the type of gel electrophoresis used, while able to separate DNA quantitatively (i.e., according to size), cannot separate equal-sized fragments qualitatively (i.e., according to base sequence).

\section{APPLICATIONS OF RAPD}

Because of the simplicity and low cost of the RAPD technique, it has found a wide range of applications in many areas of biology. Some of the areas where the technique is used are described below.

\subsection{Genetic Mapping}

Restriction Fragment Length Polymorphisms (RFLPs) have been commonly used to mapgenes (Botstein et al., 1980). This approach involves hybridisation of a probe (usually a cloned fragment) to Southern blotted genomic DNA digested with restriction endonucleases. A useful probe will detect differences in restriction fragment lengths arising from loss or gain of recognition sites or from deletions or insertions of stretches of DNA between sites (White et al., 1985; White and Lalouel, 1988). Alternatively, the RAPD technique could provide a ready source of hybridisation probes for standard Southern blot analysis simply by isolating bands from gels to detect RFLPs. However some polymorphic RAPD bands are not suitable as RFLP probes because of hybridisation to repetitive DNA sequences.

\subsection{Developing Genetic Markers Linked to a Trait in Question}

One of the most widely used applications of the RAPD technique is the identification of markers linked to traits of interest without the necessity for mapping the entire genome.

Martin et al. (1991) have described an efficient method based on the RAPD technique to isolate DNA segments linked to certain traits. This approach based on Near-Isogenic Lines (NILs) is accomplished by repeatedly backcrossing a line carrying a gene of interest (donor parent) to a cultivated line having otherwise desirable characteristics (recurrent parent).

\subsection{Population and Evolutionary Genetics}

The advances in DNA techniques have had a great impact in addressing problems in many aspects of biology. Kumari et al. (2013) used RAPD for the population based study. She found that Dendrogram based on Nei's genetic distance using Unweighted Pair Group Method of Arithmetic Means (UPGMA) indicated relative closeness and distance of the two goat breed namely Black Bengal and Black Bengal type goats of Jharkhand (Jharkhand Black). This study was mainly done on breeds raised in marginal agricultural areas in order to assist in situ conservation. The result was important with respect to puzzle of goat genetic diversity and conservation.

Application of DNA-based approaches to population genetic studies has been limited, probably due to the need 
for large samples of individuals from each population to provide an accurate estimate of allele and genotype frequencies. RAPD markers are more suitable for clonal organisms than sexually reproducing organisms.

As they breed asexually, a polymorphic fragment among individuals can be used to determine clonal identity (Williams et al., 1990; Skibinski, 1994). Species-specific markers were developed in species and strains of microorganism (Welsh and McClelland, 1990; Skibinski, 1994; Fani et al., 1993). Clone-specific markers have been identified in hydroids (Hadrys et al., 1992) and in fungal mycelia (Smith et al., 1992).

\subsection{Plant and Animal Breeding}

Genetic improvement of animals is limited by the fact that most traits of economic importance are polygenic in nature and are influenced by a variety of external (environmental) and internal factors. Such traits are termed quantitative traits and polygenic loci involved in their expression are termed Quantitative Trait Loci (QTL). The ability of the RAPD technique to reveal intra-specific variation can be used in screening for the degree of inbreeding in commercial plant and animal species to prevent an increase in the frequency of deleterious recessive alleles in populations.

\subsection{Reproducibility of RAPD Markers}

Although the RAPD method is relatively fast, cheap and easy to perform in comparison withother methods that have been used as DNA markers, the issue of reproducibility has been of much concern since the publication of the technique. In fact, ordinary PCR is also sensitive tochanges in reaction conditions, but the RAPD reaction is far more sensitive than conventional PCR because of the length of a single and a laboratory arbitrary primer used to amplify anonymous regions of a given genome.

\subsection{Limitations of RAPD}

Nearly all RAPD markers are dominant, i.e., it is not possible to distinguish whether a DNA segment is amplified from a locus that is heterozygous (1 copy) or homozygous (2copies). Co-dominant RAPD markers, observed as different sized DNA segments amplified from the same locus, are detected only rarely PCR is an enzymatic reaction, therefore the quality and concentration of template DNA, concentrations of PCR components and PCR cycling conditions may greatly influence the outcome. Thus the RAPD technique is notoriously laboratory dependent and needs carefully developed laboratory protocols to be reproducible.
Mismatches between the primer and the template may result in the total absence of PCR product as well as in a merely decreased amount of the product. Thus, the RAPD results can be difficult to interpret. PCR is an enzymatic reaction, therefore the quality and concentration of template DNA, concentrations of PCR components and the PCR cycling conditions may greatly influence the outcome.

\section{CONCLUSION}

RAPD is probably the easiest and cheapest methods for laboratory just beginning to use molecular markers. RAPD markers have found a wide range of applications in gene mapping, population genetics, molecular evolutionary genetics and plant and animal breeding. This is mainly due to the speed, cost and efficiency of the RAPD technique to generate large numbers of markers in a short period compared with previous methods. Therefore, RAPD technique can be performed in a moderate laboratory for most of its applications. Despite the reproducibility problem, the RAPD method will probably be important as long as other DNA-based techniques remain unavailable in terms of cost, time and labour.

\section{REFERENCES}

Ahn, B.H., Y.D. Ko and Y.S. Park, 1999. Study on DNA fingerprinting in han woo cattle. Korean J. Anim. Sci., 41: 577-588.

Botstein, D., R.L. White, M. Skolnick and R.W. Davis, 1980. Construction of a genetic linkage map in man using restriction fragment length polymorphisms. Am. J. Human Genetics, 32: 314-331. PMID: 6247908

Caetano-Annoles, G., B.J. Bassam and P.M. Gresshoff, 1991. DNA amplification fingerprinting using very short arbitrary oligonucleotide primers. Nat. Biotechnol., 9: 553-557. DOI: 10.1038/nbt0691-553

Cao, D. and J.H. Oard, 1997. Pedigree and RAPD-based DNA analysis of commercial U.S. rice cultivars. Crop Sci., 37: 1630-1635. DOI: 10.2135/cropsci1997.0011183X003700050037x

Clamp, P.H., R. Felters-Shalhevet, D. Beever, J. E. Atac and L.B. Schook, 1993. Linkage relationship between ALPL, EN01, GP1, PGD and TGFB1 on porcine chromosome 6. Genomics. Biochem. Syst. Ecol., 33: 171-186. 
Cushwa, W.T., K.G. Dodds, A.M. Crawferd and J.F. Medrano, 1996. Identification and genetic mapping of Random Amplified Polymorphic DNA (RAPD) markers to the sheep genome. Mann. Genome, 7: 580-585. PMID: 8678977

Erlich, H.A., 1989. PCR Technology: Principles and Applications for DNA Amplification. 1st Edn., Macmillan Publishers, New York, ISBN-10: 093585956X, pp: 246.

Excoffier, L., G. Laval and S. Schneider, 2007. Arlequin ver. 3.0: An integrated software package for population genetics data analysis. Evolut. Bioinformat. Online, 23: 47-50. PMID: 19325852

Excoffier, L., P. Smouse and J. Quattro, 1992. Analysis of molecular variance inferred from metric distances among DNA haplotypes: Application to human mitochondrial DNA restriction data. Genetics, 131: 479-491.

Fani, R., G. Damiani, C.D. Serio, E. Gallari and A. Grifoni et al., 1993. Use of Random Amplified Polymorphic DNA (RAPD) for generating specific DNA probes for microorganisms. Mol. Ecol., 2: 243-250. DOI: $\quad 10.1111 / \mathrm{j} .1365-$ 294X.1993.tb00014.X

Fukuoka, S., K. Hosaka and O. Kamijima, 1992. Use of Random Amplified Polymorphic DNAs (RAPDs) for identification of rice accessions. Japanese $\mathrm{J}$. Genet., 67: 243-252.

Galli, E.E. and M. Satti, 2009. Genetic characterizatio n of two sudanese goat beeds (Capra Hircus) using RAPD molecular markers. Afr. J. Biol., 8: 20832087.

Gwakiska, P.S., S.J. Kemp and A.J. Teale, 1994. Characterization of Zebu cattle breeds in Tanzania using random amplified polymorphic DNA markers. Ani. Genet., 25: 89-94. DOI: 10.1111/j.13652052.1994.tb00085.x

Hadrys, H., M. Balick and B. Schierwater, 1992. Applications of Random Amplified Polymorphic DNA (RAPD) in molecular ecology. Mol. Ecol., 1: 55-63. DOI: 10.1111/j.1365-294X.1992.tb00155.x

Kantanen, J., J. Vilkko, K. Elo and A.M. Tanila, 1995. Random amplified polymorphic DNA in cattle and sheep: Application for detecting genetic variation. Anim. Genet., 25: 315-320. PMID: 7486248

Kemp, S.J. and A.J. Teale, 1992. Random Amplified Polymorphisms DNA (RAPDs) and pooled DNA bovine genetic study. Anim. Genet., 23: 62-62.
Khanuja, S.P.S., A.K. Shasany, A. Pawar, R.K. Lal and M.P. Darokar et al., 2005. Essential oil constituents and RAPD markers to establish species relationship in Cymbopogon Spreng. (Poaceae). Biochem. Systemat. Ecol., 33: 171-186. DOI: 10.1016/j.bse.2004.06.011

Kimura, M. and J.F. Crow, 1964. The number of alleles that can be maintained in a finite population. Genetics, 49: 725-738. PMID: 14156929

Kumari, N., 2010. Molecular Characterization of goat genetic resources of West Bengal and Jharkhand.

Kumari, N., L.B. Singh and S. Kumar, 2013. Molecular characterization of goats using random amplified polymorphic DNA. Am. J. Anim. Vet. Sci., 8: 4549. DOI: 10.3844/ajavsp.2013.45.49

Lewontin, R.C., 1972. The Apportionment of Human Diversity. In: Evolutionary Biology, Dobzhansky, T., M.K. Hecht and W.C. Steere (Eds.), Springer, pp: 381-398.

Lowe, A.J., O. Hanotte and L. Guarino, 1996. Standardization of molecular Genetic techniques for the characterization of germplasm collections: The case of Random Amplified Polymorphic DNA (RAPD). Plant Genet. Res. Newslett., 107: 50-54.

Mackill, D.J., 1995. Classifying japonica rice cultivars with RAPD markers. Crop Sci., 35: 889-894. DOI: 10.2135/cropsci1995.0011183X003500030043x

Manly, B.F.J., 1985. The Statistics of Natural Selection on Animal Populations. 1st Edn., Chapman and Hall, London, ISBN-10: 0412256304, pp: 484.

Martin, G.B., J.G. Williams and S.D. Tanksley, 1991. Rapid identification of markers linked to a Pseudomonas resistance gene in tomato by using random primers and near-isogenic lines. Proc. Natl. Acad. Sci., 88: 2336-2340. DOI: 10.1073/pnas.88.6.2336

Munthali, M., B.V. Ford-Lloyd and H.J. Newbury, 1992. The random amplification of polymorphic DNA for fingerprinting plants. PCR Methods Appl., 1: 274-276. PMID: 1477663

Muz, A., A. Klic, G. Ozbey and H.B. Ertas, 2005. Random Amplified Polymorphic DNA (RAPD) analysis of Pasteurella multocida and Manheimia haemolytica strains isolated from cattle, sheep and goats. University of Firat, Elazig (Turkey).

Padmesh, P., K.K. Sabu, S. Seeni and P. Pushpangadan, 1998. The use of RAPD in assessing genetic variability in Andrographis paniculata Nees, a hepatoprotective drug. Research Institute. 
Qian, Q., H. Chen, Z.X. Sun and L.H. Zhu, 1996. The study on determining true and false hybrid rice II you 63 using RAPD molecular markers. Chinese J. Rice Sci., 10: 241-242.

Raghunathachari, P., V.K. Khanna, U.S. Singh and N.K. Singh, 2000. RAPD analysis of genetic variability in Indian scented rice germplasm. Curr. Sci., 79: 994998.

Rajora, O.P. and A. Mosseler, 2001. Challenges and opportunities for conservation of forest genetic resources. Euphytica, 118: 197-212. DOI: 10.1023/A: 1004150525384

Sambrook, J., E.F. Fritsch and T. Maniatis, 1989. Molecular Cloning: A Laboratory Manua. 2nd Edn., Cold Spring Harbor Laboratory, ISBN-10: 0879693096, pp: 3.

Shashikanth, P.B., 1999. Study on DNA polymorphism in cattle and buffalo. Ph.D. Thesis, NDRI Deemed University, Karnal, India.

Shivakumar, B.M., 1997. Molecular characterization of Indian cattle breeds using RAPD. M.Sc. Thesis, IVRI, Izatnagar, Bareilly.

Skibinski, D.O.F., 1994. Potential of DNA Techniques in the Population and Evolutionary Genetics of Aquatic invertebrates. In: Genetics and Evolution of Aquatic Organisms, Beaumont, A. (Ed.). Chapman and Hall, London, ISBN-10: 0412493705, pp: 177199.

Smith, M.L., J.N. Bruhn and J.B. Anderson, 1992. The fungus Armillaria bulbosa is among the largest and oldest living organisms. Nature, 356: 428-431. DOI: $10.1038 / 356428 \mathrm{a} 0$
Weir, B.S. and C.C. Cockerham, 1984. Estimating Fstatistics for the analysis of population structure. Evolution, 38: 1358-1370.

Welsh, J. and M. McClelland, 1990. Fingerprinting genomes using PCR with arbitrary primers. Nucl. Acids Res., 18: 7213-7218. PMID: 2259619

White, R. and J.M. Lalouel, 1988. Chromosome mapping with DNA markers. Scient. Am., 258: 20-28. PMID: 2903549

White, R., M. Leppert, D.T. Bishop, D. Barker and J. Berkowitz et al., 1985. Construction of linkage maps with DNA markers for human chromosomes. Nature, 313: 101-105. DOI: 10.1038/313101a0

Williams, J.G.K., A.R. Kubelik, K.J. Livak, J.A. Rafalski and S.V. Tingey, 1990. DNA polymorphisms amplified by arbitrary primers are useful as genetic markers. Nucl. Acids Res., 18: 6531-6535. PMID: 1979162

Yadav, A. and B.R. Yadav, 2007. Genetic diversity among six breeds of indian goat using RAPD markers. Biotechnology, 6: 57-60. DOI: 10.3923/biotech.2007.57.60

Yeh, F.C., T. Boyle, Y. Ronagcai, Z. Ye and J.M. Xian, 1999. POPGENE version 1.31: Quick User Guide. University of Alberta.

Yu, K.F. and K.P. Pauls, 1992. Optimization of the PCR program for RAPD analysis. Nucl. Acids Res., 20: 2606-2606. DOI: 10.1093/nar/20.10.2606 